\title{
Factors Responsible for Diabetes Elevated Blood Pressure Among Bangladeshi Adults
}

\author{
KC Bhuyan* \\ Department of Statistics, Jahangirnagar University, Savar, Dhaka, Bangladesh
}

*Corresponding author: KC Bhuyan, Department of Statistics, Jahangirnagar University, Savar, Dhaka, Bangladesh

\begin{abstract}
The analytical results presented here were based on data collected from 960 adults of ages 18 years and above residing in both urban and rural areas of Bangladesh. The data were collected by some doctors and nurses from and nearby their working places according to quota sampling plan. The objective of the study was to investigate the impacts of different socioeconomic variables on simultaneous sufferings of adults from diabetes and high blood pressure and to identify the most responsible variables for this suffering. The analysis indicated that 5.4 percent adults were simultaneously suffering from both diabetes and elevated blood pressure. The most responsible variable for the diseases was occupation followed by gender variation, income and expenditure. The results of risk ratio and factor analysis indicated that the females and physically inactive adults had the more chance of affecting by the disease. Males, non- user of can food and skilled or unskilled working group had less chance of affected by the disease. The variables were identified by factor analysis.
\end{abstract}

Keywords: Diabetes; Elevated Blood Pressure; Socioeconomic Variables; Risk Ratio; Standard Error of ln (Risk Ratio); Factor Analysis; Factor Loading

\section{Introduction}

Diabetes is one of the most risky health hazard which can enhance many non-communicable diseases like cardiovascular diseases, hypertension, kidney diseases, retinopathy, sensory system and so -fourth. Again, hypertension and or elevated blood pressure, though it is curable NCDs, is the primary risk factor for cardiovascular disease including stroke, heart failure, heart attack and aneurysm [1-8]. The elevated blood pressure is considered if systolic blood pressure is greater than or equal to $140 \mathrm{mmHg}$ and diastolic blood pressure is greater than or equal to $90 \mathrm{mmHg}[9,10]$. In 2015, I in 4 men and 1 in 5 women had hypertension [1]. Number of adults with hypertension increased from 594 million in 1975 to 1.13 billion in 2015 [1,11]. The increase was noted in low-and middle-income countries. The prevalence rate was 28.6 percent among adults of ages 18 years and above [3]. Prevalence was increased significantly with age, ranging from 6.8 percent among individuals aged 18 to 39 years to 30.4 percent in those aged 40 to 59 years and 66.7 percent in individuals aged 60 years and above [4]. In Bangladesh, according to JNC 7 guidelines the prevalence of hypertension was 17.9 percent [10].
Urban adults, elderly adults, adults with physical inactivity, obese and diabetic adults were more likely to have hypertension [10]. People with both diabetes and hypertension have approximately twice the risk of cardiovascular diseases compared to the people with non-diabetic hypertension [12]. The prevalence of hypertension among diabetic patients is around three times compared to the people of non-diabetic hypertension [13]. Diabetes is the targeted disease by WHO as it has some social and economic consequences [14-17]. Accordingly, the problem is addressed to reduce the prevalence of the disease. Still, upward trend in deaths due to diabetes is noted [16]. This is true for both home and abroad [17]. It was reported that, approximately 463 million adults of ages 20-79 years worldwide were diabetic [17]. This figure will be increased up to 700 million in 2045. In a separate report, it was mentioned that 1 in 5 diabetic patients were at the age above 65 years and 2 in 3 were urban residents $[18,19]$.

In one study, it was observed that most of the Bangladeshi urban adults (36.3\%) were suffering from diabetes [20]. Both diabetes and hypertension are in alarming stage for elderly people in both 
home and abroad. Thus, the simultaneous impact of diabetes and elevated blood pressure needs to be considered and how these diseases are influenced by different socioeconomic variables are needed to be studied. For this reason, the objective of the study was to observe the association of the prevalence of both the diseases simultaneously with different socioeconomic variables and to identify the variables responsible for both the diseases among adults. The responsible variables were identified by factor analysis.

\section{Methodology}

The present work was done by analyzing the data collected from adults of ages 18 years and above residing in both urban and rural areas of Bangladesh. The investigated adults were 960. They were available for investigation nearby the working places of some doctors and nurses when they were doing their Master of Public Health degree in American International UniversityBangladesh during the academic session 2017-18. These adults were investigated by quota sampling method to cover around $70 \%$ diabetic patients [21]. The objective to cover this number of diabetic patients was to ensure a good amount of elevated blood pressure people simultaneously suffering from diabetes [1]. For comparative study, a good number of normal subjects were also investigated. Finally, 960 adults were interviewed, and data were recorded through a pre-designed and pre-tested questionnaire.

The questionnaire contained different questions related to different socioeconomic variables of the respondents and of the families. The main questions for families were related to the monthly family income and monthly family expenditure. The questions for the diabetic adults were related to the duration of disease, disease related health hazard, i.e. eye problem, kidney problem, heart problem, blood pressure, blood sugar, treatment stage of disease, admission into hospital, etc. Beside these, the other questions were related to personal habit, viz. food habit, working habit, physical activity, utilization of time, etc. The collected personal information were residence, religion, marital status, age, height, weight, education, and occupation. Some of the above-mentioned variables were qualitative and some were quantitative in nature. All the recorded variables were measured in nominal scale by assigning numbers. Height and weight were used to measure the level of obesity and level of obesity was measured by the value of
BMI, where BMI was calculated by weight (in $\mathrm{kg}$ ) divided by height (in meter $^{2}$ ). The respondents were classified as underweight (BMI $<20$ ), normal (BMI = 20 and above but less than 25), overweight (BMI $=25$ and above but less than 30 ) and obese (BMI $\geq 30$ ).

At the first step of analysis, association of level of prevalence of diabetes and prevalence of elevated blood pressure [if diastolic blood pressure $\geq 90 \mathrm{mmHg}$ and systolic blood pressure $\geq 140 \mathrm{mmHg}$ ] was investigated. The association of socioeconomic variables and prevalence of diabetes and high blood pressure were investigated by Chi-square test, where significant association was decided if the p-value of Chi-square statistic is less than or equal to 0.05 . Some diabetic adults were at higher risk of elevated blood pressure compared to others. To study this characteristic the risk ratio (R.R.) along with standard error of ln (R.R.) for a particular level of a social variable compared to the level of the variable which did not create problem for the disease was calculated. Factor analysis was done to identify the most responsible variables to create problems simultaneously for diabetes and high blood pressure among the adults. Important variables which did not create simultaneously problem of diabetes and higher blood pressure among adults were also detected. The importance of the variables were decided by the highest absolute value of factor loading [22, 23]. The analysis was done using the SPSS [Version 25].

\section{Result}

The investigated adults were classified into two groups according to the prevalence of diabetes. There were 66.9 percent diabetic respondents and 8.1 percent of them were suffering from high blood pressure (Table 1) also. The prevalence of diabetes and prevalence of high blood pressure were significantly associated as is observed by Chi-square test $\left[\chi^{2}=20.17, \mathrm{p}\right.$-value $\left.=0.000\right]$. The diabetic patients were at higher risk of high blood pressure by 45 percent compared to the risk of non-diabetic adults [R.R $=1.45$, S.E. $\ln ($ R.R. $)=0.0405]$. It was also observed that 5.7 percent adults were suffering from elevated blood pressure but 94.5 percent of them were the patients of diabetes also. They were suffering for different periods. Eight of them were suffering for less than 5 years, 18 were suffering for 5 but less than 10 years, 11 were suffering for 10 to less than 15 years and 15 were suffering for 15 years and above.

Table 1: Distribution of respondents according to prevalence of diabetes and prevalence of high blood pressure.

\begin{tabular}{|c|c|c|c|c|c|c|}
\hline \multirow{3}{*}{$\begin{array}{l}\text { Prevalence } \\
\text { of high blood } \\
\text { pressure }\end{array}$} & \multicolumn{4}{|c|}{ Prevalence of diabetes } & \multirow{2}{*}{\multicolumn{2}{|c|}{ Total }} \\
\hline & \multicolumn{2}{|c|}{ No } & \multicolumn{2}{|c|}{ Yes } & & \\
\hline & $\mathbf{n}$ & $\%$ & $\mathbf{n}$ & $\%$ & $\mathbf{n}$ & $\%$ \\
\hline Yes & 3 & 0.9 & 52 & 8.1 & 55 & 5.7 \\
\hline No & 315 & 99.1 & 590 & 91.9 & 905 & 94.3 \\
\hline Total & 318 & 33.1 & 642 & 66.9 & 960 & 100 \\
\hline
\end{tabular}


In the sample, the rural adults were 43.5 percent and 6.5 percent of them were simultaneously suffering from diabetes and high blood pressure (Table 2). Among urban adults the percentage of sufferers from both the diseases was 4.6. This differential in proportions was not statistically significant $\left[\chi^{2}=1.571, \mathrm{p}-\right.$ value $\left.=0.210\right]$. But rural adults were at $40 \%$ more risk of affecting from both the diseases compared to the risk of urban adults [R.R.= 1.40, S.E $\ln$ (R.R.) $=0.96$. Among the investigated adults 44.8 percent were females and 6.7 percent of them were suffering from the aforesaid disease. The corresponding percentage among males was lower (4.3\%). But the difference in percentages was statistically similar $\left[\chi^{2}=2.679, \mathrm{p}-\right.$ value $=0.102]$. However, females were at 55 percent more risk of the disease compared to the risk of males [ R.R. $=1.55$, S.E. In (R.R.) $=0.27$ ]; R.R. $=0.64$, S.E. $\ln$ (R.R.) $=0.27$, respectively] . The females are usually housewives. But this study indicated that most of the females were not housewives as the number of adults in this group was 331. In this group students and employed adults were also included. This group were usually not involved in physical labor and for that reason they had the more risk of affecting by diabetes and diabetes related disease. This fact was noted in different studies [24-26]. The present study also supported the fact, though there was no significant association between occupation and prevalence of the diseases under study $\left[\chi^{2}=3.635, \mathrm{p}-\right.$ value $\left.=0.304\right]$. But still housewives, students and unemployed adults had 63 percent more risk of affecting by the disease compared to the risk of other adults [R.R. $=1.63$, S.E. $\ln$ (R.R.) $=0.27$ ] Skilled or unskilled physical labourers had lower risk of affecting by the disease [R.R. $=0.82$, S.E $(R \cdot R)=0.60]$.

Table 2: Distribution of adults according to prevalence of diabetes high blood pressure and some Socioeconomic variables.

\begin{tabular}{|c|c|c|c|c|c|c|}
\hline \multirow{3}{*}{ Socioeconomic variables } & \multicolumn{4}{|c|}{ Prevalence of diabetic elevated blood pressure } & \multirow{2}{*}{\multicolumn{2}{|c|}{ Total }} \\
\hline & \multicolumn{2}{|c|}{ Yes } & \multicolumn{2}{|c|}{ No } & & \\
\hline & $\mathbf{n}$ & $\%$ & $\mathbf{N}$ & $\%$ & $\mathbf{n}$ & $\%$ \\
\hline \multicolumn{7}{|c|}{ Residence } \\
\hline Rural & 27 & 6.5 & 391 & 93.6 & 418 & 43.5 \\
\hline Urban & 25 & 4.6 & 517 & 95.4 & 542 & 56.5 \\
\hline Total & 52 & 5.4 & 908 & 95.6 & 960 & 100 \\
\hline \multicolumn{7}{|c|}{ Gender } \\
\hline Male & 23 & 4.3 & 507 & 95.7 & 530 & 55.2 \\
\hline Female & 29 & 6.7 & 401 & 93.3 & 430 & 44.8 \\
\hline \multicolumn{7}{|c|}{ Religion } \\
\hline Muslim & 42 & 5.3 & 751 & 94.7 & 793 & 82.6 \\
\hline Non-Muslim & 10 & 6 & 157 & 94 & 167 & 17.4 \\
\hline \multicolumn{7}{|c|}{ Marital status } \\
\hline Currently married & 42 & 6.3 & 628 & 93.7 & 670 & 69.8 \\
\hline Currently single & 10 & 3.4 & 280 & 96.6 & 290 & 30.2 \\
\hline \multicolumn{7}{|c|}{ Age ( in years) } \\
\hline$<20$ & 0 & 0 & 28 & 100 & 28 & 2.9 \\
\hline $20-30$ & 6 & 3.7 & 156 & 96.3 & 162 & 16.9 \\
\hline $30-40$ & 10 & 4 & 240 & 96 & 250 & 26 \\
\hline $40-50$ & 12 & 4.5 & 252 & 95.5 & 264 & 27.5 \\
\hline $50+$ & 24 & 9.4 & 232 & 90.6 & 256 & 26.7 \\
\hline \multicolumn{7}{|c|}{ Education } \\
\hline Illiterate & 6 & 11.1 & 48 & 88.9 & 54 & 5.6 \\
\hline Primary & 11 & 9.6 & 104 & 90.4 & 115 & 12 \\
\hline Secondary & 6 & 2.6 & 223 & 97.4 & 229 & 23.9 \\
\hline Higher & 29 & 5.2 & 533 & 94.8 & 562 & 58.5 \\
\hline \multicolumn{7}{|c|}{ Occupation } \\
\hline Agriculture and unskilled labor & 12 & 4.7 & 243 & 95.3 & 255 & 26.6 \\
\hline Business and skilled labor & 8 & 5 & 153 & 95 & 161 & 16.8 \\
\hline Service & 8 & 3.8 & 205 & 96.2 & 213 & 22.2 \\
\hline Housewives and others & 24 & 7.3 & 307 & 92.3 & 331 & 34.5 \\
\hline
\end{tabular}




\begin{tabular}{|c|c|c|c|c|c|c|}
\hline \multicolumn{7}{|c|}{ Income ( in 000 taka) } \\
\hline$<40$ & 7 & 2.3 & 304 & 97.7 & 311 & 32.4 \\
\hline $40-60$ & 3 & 1.6 & 186 & 98.4 & 189 & 19.7 \\
\hline $60-80$ & 5 & 2.7 & 183 & 97.3 & 188 & 19.6 \\
\hline $80-100$ & 4 & 2.5 & 156 & 97.5 & 160 & 16.7 \\
\hline $100+$ & 5 & 4.5 & 107 & 95.5 & 112 & 11.6 \\
\hline \multicolumn{7}{|c|}{ Family expenditure ( in 000 taka) } \\
\hline$<30$ & 6 & 5.2 & 110 & 94.8 & 116 & 12.1 \\
\hline $30-50$ & 13 & 4.4 & 282 & 95.6 & 295 & 30.7 \\
\hline $50-70$ & 11 & 5.3 & 197 & 94.7 & 208 & 21.7 \\
\hline $70-90$ & 8 & 4.5 & 169 & 95.5 & 177 & 18.4 \\
\hline $90+$ & 14 & 8.5 & 150 & 91.5 & 164 & 17.1 \\
\hline \multicolumn{7}{|c|}{ Taking restaurant food } \\
\hline Yes & 36 & 7.3 & 457 & 92.7 & 493 & 51.4 \\
\hline No & 16 & 3.4 & 451 & 96.6 & 467 & 48.6 \\
\hline Total & 52 & 5.5 & 908 & 94.5 & 960 & 100 \\
\hline \multicolumn{7}{|c|}{ Utilization of time } \\
\hline Read and use mobile phone & 1 & 0.7 & 138 & 99.3 & 139 & 14.5 \\
\hline Do household work and watch T.V. & 6 & 2.5 & 235 & 97.5 & 241 & 25.1 \\
\hline Play and use mobile phone & 12 & 4.9 & 235 & 95.1 & 247 & 25.7 \\
\hline Read paper and use mobile after office work & 10 & 4 & 239 & 96 & 249 & 25.9 \\
\hline Watch T.V. and use mobile phone after office work & 23 & 27.4 & 61 & 72.6 & 84 & 8.8 \\
\hline \multicolumn{7}{|c|}{ Physical work } \\
\hline Yes & 15 & 4.3 & 336 & 95.7 & 351 & 36.6 \\
\hline No & 37 & 6.1 & 572 & 93.9 & 609 & 63.4 \\
\hline \multicolumn{7}{|c|}{ Smoking habit } \\
\hline Yes & 20 & 5.4 & 351 & 94.6 & 371 & 38.6 \\
\hline No & 32 & 5.4 & 557 & 94.6 & 589 & 61.4 \\
\hline Total & 52 & 5.4 & 908 & 94.6 & 960 & 100 \\
\hline \multicolumn{7}{|c|}{ Obesity } \\
\hline Underweight & 3 & 3.5 & 82 & 96.5 & 85 & 8.9 \\
\hline Normal & 19 & 4.2 & 437 & 95.8 & 456 & 47.5 \\
\hline Overweight & 16 & 4.9 & 311 & 95.1 & 327 & 34.1 \\
\hline Obese & 14 & 15.2 & 78 & 84.8 & 92 & 9.6 \\
\hline Total & 52 & 5.4 & 908 & 94.5 & 960 & 100 \\
\hline \multicolumn{7}{|c|}{ Habit of taking can food } \\
\hline Yes & 41 & 7 & 543 & 93 & 584 & 60.8 \\
\hline No & 11 & 2.9 & 365 & 97.1 & 376 & 39.2 \\
\hline Total & 52 & 5.5 & 908 & 94.5 & 960 & 100 \\
\hline
\end{tabular}

The non-Muslim adults were 17.4 percent only and 6.0 percent of them were suffering from the disease. This percentage among Muslim adults was slightly less (5.3\%). But there was no significant association between religion and prevalence of diabetes high blood pressure $\left[\chi^{2}=0.129\right.$, $\mathrm{p}$ value $\left.=0.720\right]$. Even then, the nonMuslim adults were at higher risk of the disease compared to the risk of Muslim adults [R.R. $=1.13$, S.E ln (R.R.) $=0.34$ ]. Most of the investigated adults $(69.8 \%)$ were currently married and 6.3 percent of them were suffering from the prevalence of diabetes high blood pressure. This percentage among currently single adults was 3.4. But this difference in percentages was not statistically significant as was observed by Chi-square test where $\chi^{2}=3.132$ with $\mathrm{p}$ value $=0.076$. But currently married adults were at 82 percent more risk of the disease compared to the risk of currently single adults [R.R. $=1.82$, S.E. $\ln ($ R.R $)=0.40]$. In studying different aspects of non-communicable diseases using the same set of data it was noted that the diseases were prevalent among elderly people $[24,25,27]$. The same phenomena was noted in this case also. The 
prevalence of diabetes higher blood pressure was significantly different among adults of different ages $\left[\chi^{2}=11.731, \mathrm{p}\right.$ - value $=0.019]$. The rate of prevalence was in increasing trend with the increase in ages of adults and this rate was higher (9.4\%) among adults of ages 50 years and above. The elderly adults of ages 40 years and above had 69 percent more risk of suffering from the disease compared to the risk of younger adults [R.R.= 1.69, S.E. In (R.R.) $=0.29$ ] . Higher proportion of illiterate (11.1\%) and primary educated adults $(11.6 \%)$ were suffering from diabetes and high blood pressure. The different proportions of adults suffering from the disease was significantly different $\left[\chi^{2}=10.849, \mathrm{p}\right.$ value $=$ 0.013]. In the sample the higher educated adults were 562 and 5.2 percent of them were suffering from the disease. The percentages of illiterate and primary educated adults suffering from the disease were 11.1 and 9.6, respectively. The illiterate and primary educated adults had more than two times risk of the diseases compared to the risk of secondary and higher educated adults [R.R.= 2.27, S.E. ln (R.R.) = 0.28]. The percentage of adults coming from highest income group (Tk. 100.00 thousand and above) of families was 11.6 and 8.9 percent of them were suffering from the disease. Lowest proportion of affected adults (4.2\%) were noted in lower income families (income < Tk. 60.00 thousand). But the differences in proportions of adults of different families of different levels of income were not statistically significant $\left[\chi^{2}=5.642, \mathrm{p}\right.$ value $=$ 0.227]. However, adults belonged to families of highest income level were at 80 percent more risk of the disease compared to the risk of adults of lower income group of families [R.R = 1.80, S.E.ln(R.R )= 0.34 ]. Similar results were noted in case of family expenditure of adults spending highest amount of money [R.R. = 1.79, S.E. In (R.R.) $=0.30]$.

The present analysis indicated that 34.7 percent adults were involved in sedentary activities and 9.9 percent of them were affected by diabetes and elevated blood pressure. Another big group $(25.7 \%)$ of adults were also passing their time watching television but they did household work also. A smaller proportion $(2.5 \%)$ of them were suffering from diabetes high blood pressure. The proportions of affected adults involved in different activities except physical work were significantly different $\left[\chi^{2}=90.218\right.$, pvalue $=0.000]$. Those who were only involved in sedentary activities were at higher risk of the disease by 827 percent compared to the risk of other adults [R.R. $=8.27$, S.E. $\ln ($ R.R.) $=0.25]$. The percentage of physically inactive adults was 63.4 and 6.1 percent of them were affected by diabetes and elevated blood pressure. The corresponding percentage among physically active adults was 4.3. This difference in proportions was not significant. But physically inactive adults had a higher risk of suffering from the disease by 42 percent compared to the risk of other adults [R.R. $=1.42$, S.E. In
(R.R.) $=0.30]$.

The percentage of obese adults in the sample was 9.6 and 15.2 percent of them were affected by the prevalence of diabetic high blood pressure. With the increase in level of obesity there was an upward movement in the percentage of affected adults. Significant association between level of obesity and prevalence of diabetic elevated blood pressure was observed $\left[\chi^{2}=19.405\right.$, $\mathrm{p}$ - value $=$ 0.000]. The obese adults were at risk of the disease which was more than 3 times than the risk of non-obese adults [R.R $=3.48$, S.E. $\ln$ (S.E.) $=0.29$ ]. The analysis of the data showed that 51.4 percent adults had the habit of taking restaurant food and 7.3 percent of them were affected by the disease. This group of adults were at risk by more than two times compared to the risk of adults who were not habituated in taking restaurant food [R.R.=2.13, S.E. In (R.R.) $=0.29$ ]. The habit of taking restaurant food was significantly associated with prevalence of diabetic high blood pressure [ $\chi^{2}=$ $7.033, \mathrm{p}-$ value $=0.008]$. Similar was the case for the adults who were taking can food $\left[\chi^{2}=7.487, \mathrm{p}-\right.$ value $=0.000$; R.R. $=2.40$, S.E. $\ln$ (R.R.) = 0.33]. The percentage of users of can food was 60.8 and 7.0 percent of them were suffering from the disease. For this group of adults, the risk of suffering was more than two times compared to the risk of adults who were not habituated in taking can food. The risk for adults not using can food was less [R.R.= 0.42, S.E. $(R . R)=0.33]$. Among the adults 38.6 percent were smokers and prevalence of diabetes elevated blood pressure was observed among 5.4 percent of them. But smoking habit was not associated with prevalence of diabetic elevated blood pressure $\left[\chi^{2}=0.311, p\right.$ - value $=0.577]$. Both the smoker and non-smoker adults were at similar risk of affecting by the disease [R.R.= 0.99, S.E. $\ln$ (R.R.) $=$ $0.28]$.

\section{Factor Analysis}

The analytical results presented above gave the evidence that some of the socioeconomic variables, viz. age, education, utilization of time, level of obesity, food habit and use of can food were significantly associated with the prevalence of diabetes elevated blood pressure (Table 3). But the study of this association did not indicate the most responsible factor in enhancing the afore mentioned health problem. To identify the most responsible factor for the prevalence of the disease among adults, factor analysis was done. Factors which were not enhancing the problem were also identified. Separate analyses for both affected and non-affected groups were done using all the data available for the study variables. It was already mentioned that the adults were classified into two groups. For each group important variable was identified observing the highest value of the absolute coefficient of the variables. Some variables were not included in the final selection of the coefficients 
as their communalities were less than $0.40[22,23]$. The inclusion of the variables for analysis was sufficient for both group of adults as $\mathrm{KMO}=0.585, \chi^{2}=385.731$, $\mathrm{p}$-value $=0.000$; and $\mathrm{KMO}=0.592, \chi^{2}$ $=3332.688, \mathrm{p}$ value $=0.000$, respectively (Table 3 ). For the affected adults, the most responsible variable was occupation followed by gender variation, income and expenditure. For the non-affected group, the most important variable was gender variation followed by use of can food and occupation.

Table 3: Results related to factor analysis for two groups of adults.

\begin{tabular}{|c|c|c|c|c|c|c|}
\hline \multirow[b]{2}{*}{ Variable } & \multicolumn{3}{|c|}{ Prevalence of diabetes elevated blood pressure } & \multicolumn{3}{|c|}{ Non- prevalence of diabetes elevated blood pressure } \\
\hline & $\begin{array}{c}\text { Communality, } \\
\text { initial }\end{array}$ & $\begin{array}{c}\text { Communality, } 3^{\text {rd }} \\
\text { step }\end{array}$ & Coefficient & $\underset{\text { initial }}{\text { Communality, }}$ & $\begin{array}{c}\text { Communality, } 3^{\text {rd }} \\
\text { step }\end{array}$ & Coefficient \\
\hline Residence & 0.402 & 0.464 & -0.071 & 0.081 & - & \\
\hline Religion & 0.607 & 0.644 & 0.264 & 0.111 & - & \\
\hline Gender & 0.785 & 0.688 & 0.726 & 0.837 & 0.799 & 0.869 \\
\hline Marital status & 0.436 & - & - & 0.504 & 0.561 & 0.31 \\
\hline Age & 0.481 & 0.565 & -0.391 & 0.47 & 0.547 & -0.522 \\
\hline Education & 0.543 & 0.699 & -0.289 & 0.433 & - & - \\
\hline Occupation & 0.77 & 0.876 & 0.809 & 0.539 & 0.616 & 0.651 \\
\hline Income & 0.832 & 0.782 & 0.578 & 0.896 & - & - \\
\hline Expenditure & 0.856 & 0.807 & 0.569 & 0.897 & - & - \\
\hline Utilization of time & 0.532 & 0.568 & -0.442 & 0.732 & 0.734 & -0.391 \\
\hline BMI & 0.157 & - & - & 0.096 & - & - \\
\hline Food habit & 0.171 & - & - & 0.109 & - & - \\
\hline $\begin{array}{l}\text { Habit of taking can } \\
\text { food }\end{array}$ & 0.404 & - & - & 0.771 & 0.759 & 0.859 \\
\hline Physical labor & 0.542 & 0.682 & -0.507 & 0.469 & 0.591 & -0.263 \\
\hline Duration of disease & 0.512 & 0.576 & -0.48 & 0.269 & - & - \\
\hline
\end{tabular}

\section{Discussion}

The different results discussed in this paper was derived from the data collected from 960 adults of ages 18 years and above residing in both urban and rural areas of Bangladesh. Most of the investigated adults (56.5\%) were from urban area as the data were collected by some doctors and nurses from and nearby their working places. Among the investigated adults 5.4 percent were suffering simultaneously from diabetes and high blood pressure, though the percentage of diabetic patients in the sample was higher (66.9\%). In urban area higher percentage of diabetic adults were noted in some earlier studies also $[20,21,24,25]$ and these adults were suffering from different types of non-communicable diseases. In this analysis, no significant association between residence and prevalence was observed but rural adults were at higher risk $(40 \%$ higher) of affecting by the disease compared to the risk of urban adults. This risk was higher (55\% higher) among the female adults. But prevalence of the disease was independent of the gender. The risk of suffering from the disease by male adults was lower [R.R.=0.64]. Similar findings were noted in other studies [24,25]. The independence was observed in studying the association of prevalence of the disease with religion and marital status of the adults.
In different studies, in both home and abroad, aged males and females were at higher risk of different types of non-communicable diseases including higher blood pressure [28-34]. This study also indicated that with the increase in ages there was significant increase in the prevalence rate of diabetes and high blood pressure. The adults of ages 40 years and above had the higher risk of affecting by the disease compared to the risk of younger adults. With the increase in level of education of adults there was a downward shift in the prevalence rate of diabetes elevated blood pressure. The risk of illiterate adults of affecting by the disease was more than two times than the risk of educated adults. Housewives, students and unemployed adults were not directly doing any physical labor and this physical inactivity was the important cause of higher risk of affecting by the disease. In other studies, also it was observed that this group of adults were more exposed to different types of non-communicable diseases $[24,25]$. Due to this physical inactivity factor analysis also indicated that occupation was the most important factor for the prevalence of the disease. On the other hand, skilled or unskilled workers had lower risk of affecting by the disease. It was also reflected in doing factor analysis. However, level of occupation was independent of level of prevalence of the disease.

Physical inactivity and involvement in sedentary activities are two risk factors for many types of NCDs. It was noted in both 
home and abroad [27-30]. This study also indicated that the adults involved in sedentary activities had more than 8 times risk of facing the problem of diabetes and high blood pressure simultaneously.

Obesity is one of the highly risk factor for NCDs. It was noted in both home and abroad [28-33]. This analysis provided the evidence that with the increase in level of BMI there was a significant increase in the rate of prevalence of diabetes elevated blood pressure. The obese adults had more than 3 times risk of facing the problem of diabetes and high blood pressure compared to the risk of other adults. In earlier studies it was noted that habit of taking restaurant food and can food be the risk factors for NCDs [24,25]. The present analysis showed that majority (51.4\%) of the adults were habituated in taking restaurant food and can food $(60.8 \%)$. Both these two groups of adults had more than two times risk of affecting by the disease compared to the risk of adults who were not taking either restaurant food or can food. Non-consumption of can food was the second most important factor for non-prevalence of diabetes elevated blood pressure.

\section{Conclusion}

The present paper was prepared with an objective to study the impacts of different socioeconomic variables on the prevalence of diabetes and high blood pressure among adults of ages 18 years and above. The targeted adults were investigated by some doctors and nurses from their working places using quota sampling plan to cover around 70 percent diabetic patients so that some of the diabetic adults were suffering from other non-communicable diseases also. But during data collection,66.9 percent diabetic adults were interviewed, and total investigated adults were 960 . Among these diabetic adults, 8.1percent were suffering from both diabetes and elevated blood pressure for different periods [1].

These adults were classified into 4 groups according to their sufferings for less than 5 years, $5-<10$ years, $10-<15$ years and 15 years and above. The number of total diabetic adults belonging to these 4 periods were significantly different as was observed during discriminant analysis. Among the investigated adults 43.5 percent were from rural area, 44.8 percent were females, 17.4 percent were non-Muslims, 69.8 percent were currently married, 54.2 percent were of ages 40 years and above, 5.6 percent were illiterate, 34.5 percent were housewives, students and unemployed adults. In each case of these demographic characteristics higher proportion of the adults were suffering from diabetes and high blood pressure simultaneously compared to the proportions of sufferers of their counterparts. The adults possessing these demographic characteristics were at higher risk of the diseases under consideration. So far economy concern the adults belonging to families of highest level of income and highest level of expenditure were at higher risk of the disease compared to the risk of adults of other families.
Among the adults 34.7 percent were involved in sedentary activities, 63.4 percent were physically inactive. Both these groups of adults were at higher risk of the disease compared to the risk of adults involved in some sort of physical activities. So far food habit concern, 51.4 percent were habituated in taking restaurant food and 60.8 percent were used to take can food. Both these groups of adults were at higher risk of the disease compared to the risk of their counter parts. Obese adults (9.6\%) were at higher risk of the disease compared to the risk of non-obese adults. From the results of factor analysis and risk ratio, it could be concluded that females, physically inactive adults and adults from affluent families had higher risk of affecting by the prevalence of diabetes elevated blood pressure. On the other hand, males, skilled or unskilled physical workers and non-consumers of can food were less affected by the prevalence of diabetes elevated blood pressure.

As the prevalence of the disease is associated with maximum socioeconomic variables, the problem of prevalence cannot be avoided but intensity of the problem can be reduced if some plans related to proper health care can be formulated and action is taken to implement those plans. The following steps can be taken for healthy society and reduced rate of NCDs affected people.

1. People should be encouraged to maintain healthy body weight or to reduce the BMI.

2. People should be advised to eat heart- healthy food and food free of much sugar and salt.

3. People should be encouraged to take more fresh vegetables and fruits.

4. Elderly people should consult the doctor for proper medication regularly so that blood pressure is properly controlled.

5. Each and every one should do some sort of physical work whenever it is possible.

6. Each and every one at least walk a while whenever it is possible.

7. Everyone should avoid sedentary activities as per as possible.

8. Health authority in both urban and rural areas can provide a service free of cost to check up the blood pressure, blood sugar and body weight at least twice a year. This can be done by forming different charitable trusts in the community or forming social workers groups.

\section{References}

1. WHO (2019) Hypertension. World Health Organization, Financial Report, Switzerland.

2. Hypertension Study Group (2001) Prevalence, awareness, treatment and control of hypertension among elderly in Bangladesh and India: a multicentre study. Bull World Health Organ 79(6): 490-500. 
3. Rahman M, Zaman MM, Islam JY, Chowdhury J, Ahsan HN, et al. (2018) Prevalence, treatment, patterns and risk factors of hypertension and pre-hypertension among Bangladeshi adults, Jour. Hum Hypertension 32: $334-348$.

4. Michael JB, Blumenthal RS. High blood Pressure: Prevention, Treatment and Research. Johns Hopkins Medicine, USA.

5. Chobanian AV, Bakris GL, Black HR, Cushman WC, Lee A Green, et al. (2003) Seventh Report of the Joint National Committee of Prevention, Detection, Evaluation Treatment of High Blood Pressure. JAMA 289(19): 2560-2571.

6. Everett B, Zajacova A (2015) Gender difference in hypertension and hypertension awareness among young adults. Biodemography and Social Biology 61(1): 1-17.

7. Hu FB, B Wang, C Chen, Y Jin, J Yang, et al. (2000) Body mass index and cardiovascular risk factors in a rural Chinese Population. Am J Epidemiol 151(1): 88-97.

8. Sug YS, Burt V, Tatiana Louis, Margaret D Carroll (2012) Hypertension among adults in the United States, 2009-2010. NCHS Data Brief (107): 1-8.

9. Roger VL, Go AS, Lloyd-Jones DM, Emelia J Benjamin, Jarett D Berry, et al. (2012) Heart disease and stroke statistics - 2012 update: a report from the American Heart Association. circulation 125(1): e2-e220.

10. Jasica YI, Zaman MM, Haq SA, Shamim A, Al-Quadir Z (2018) Epidemiology of hypertension among Bangladeshi adults using the 2017 ACC/ AHA Hypertension Clinical Practice Guidelines and Joint National Committee 7 Guidelines. Journal of Hypertension 32(10): 668-680.

11. Tim Newman (2019) High Blood Pressure Research: 2019 Overview, Medical News Today, UK.

12. WHO, Branca F, Nikogosian H, Lobstein T Copenhagen Editors (2007) The challenge of obesity in the WHO European region and the strategies for response. WHO, Europe PP: 1-76.

13. Bertino M, Ardiri AM, Ali FT, Boemi PMS, Cilio D, et al. (2006) Obesity and related disease: an epidemiological study in Eastern Sicily. Minerva Gastroenterol Dietol 52(4): 379-385.

14. Calamusa G, Amodio E, Costantino C, Maria D, Pasquate, et al. (2012) Body mass index and factors associated with overweight and obesity: a cross-sectional study of adult subjects living in a small city of Western Sicily (Italy). Italian Journal of Pub. Health 9(3): e7539-1 to e7539-9.

15. Bhuyan KC, Jannatul F (2019) Discriminating Bangladeshi adults by level of obesity. LOJ Med Sci 3(1): 184-191.

16. Stamler J (1991) Epidemiological findings on body mass and blood pressure in adults. Annals of Epidemiology 1(4): 347-362.

17. (1997) National High Blood Pressure Education Program Working Group Report on Hypertension in the Elderly. Hypertension 23(3): 275285.

18. Bhuyan KC (2020) Discriminating Bangladeshi adults by the prevalence of diabetic elevated blood pressure. J Endocrinol Thyroid Res 5(4): 7279.
19. Tammy M Brady (2017) Obesity- related hypertension in children. Front Pediatric 5: 197.

20. WHO (2018) Fact Sheets/detail/ obesity and overweight. February 2018, WHO, Switzerland.

21. Fardus J, Bhuyan KC (2016) Discriminating diabetic patients of some rural and urban areas of Bangladesh: A discriminant analysis approach. Euromediterrean Bio Jour 11(9): 134-140.

22. Yotoka T (1983) Some criteria for variable selection in factor analysis. Behaviormetrika 13: 31-45.

23. Ruscio J, Roche B (2012) Determining the number of factors to retain in an exploratory factor analysis using comparison data of known factorial structure. Psychological Assessment 24(2): 282-292.

24. Bhuyan KC (2020) Socioeconomic variables responsible for diabetic retinopathy among Bangladeshi adults. BJSTR 25(1): 18829-18836.

25. Bhuyan KC (2019) Identification of socioeconomic variables responsible for diabetic heart disease among Bangladeshi adults. ARC Journal of Diabetes and Endocrinology 5(2): 1-8.

26. Syed MS, Debra N, Muhammad HR, Musa R, Gul N (2004) Assessing obesity and overweight in a high mountain Pakistani population. Tropical Medicine and International Health 9(4): 526-532.

27. Bhuyan KC (2019) Factors responsible for non-communicable diseases except diabetes among Bangladeshi adults. Archives of Diabetes and Endocrine System 2(2): 22-29.

28. Akter S, Rahaman MM, Sarah KA, Sultan P (2014) Prevalence of diabetes and pre-diabetes and their risk factors among Bangladeshi adults: a nationwide survey. Bull World Health Organ 92(3): 204-213A.

29. Mokdad AH, Ford ES, Bowman BA, Dietz WH, Vinicor F, et al. (2003) Prevalence of obesity, diabetes, and obesity-related health risk factors 2001. JAMA 289(1): 76-79.

30. Silink M, Tuomilehto J, et al. (2011) Prevention and control of diabetes with a focus on low and middle-income countries, Paper 6, A Prioritized research agenda for prevention and control of NCDs.

31. Bhuyan KC, Fardus J (2019) Level of Obesity and Socioeconomic Factors of a Group of Adult People of Bangladesh: A Factor Analysis Approach. American Jour Data Mining and Knowledge Discovery 4(1): 8-14.

32. Bhuiyan D, Bhuyan KC (2019) Discriminating Bangladeshi adults by non-communicable diseases. Rehabilitation Science 4(3): 35-43.

33. Bhuyan KC, Rahman S, Fardus J (201) Body mass index and diabetes associated with socioeconomic factors among adult people of Bangladesh. [with Sadia Rahaman and Jannatul Fardus]. AJSE 16(3): 187-192.

34. Vasan RS, Beiser A, Seshadri S, Larson MG, Kannel WB, et al. (2002) Residual lifetime risk for developing hypertension in middle-aged women and men: The Framingham Heart Study. JAMA 287(8): 10031010 . 
(C) This work is licensed under Creative (c) BY Commons Attribution 4.0 License

To Submit Your Article Click Here:

Submit Article

DOI: $10.32474 / A D 0.2020 .03 .000151$

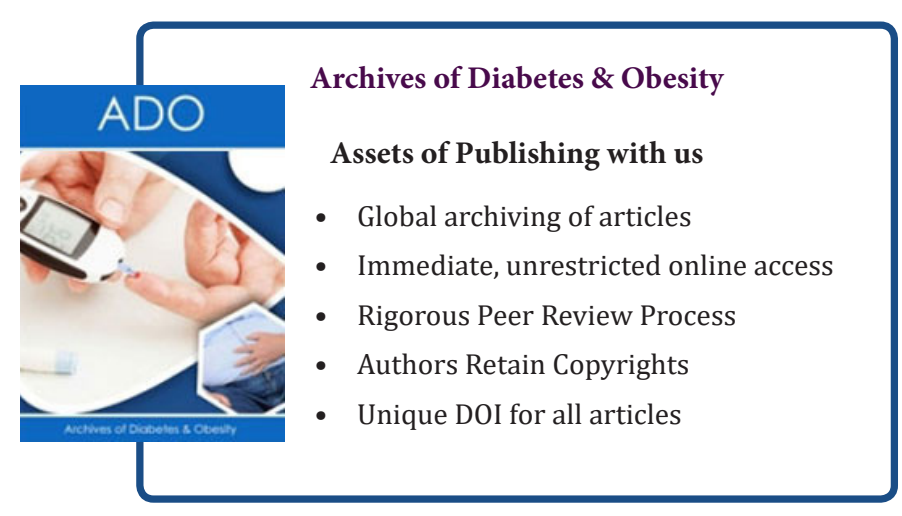

